\title{
ARTIGOS
}

Submetido 13.07.2016. Aprovado 10.11.2016

Avaliado pelo processo de double blind review. Editora Científica: Ana Maria Malik

DOI: http://dx.doi.org/10.1590/So034-759020170207

\section{VÍNCULOS PROFISSIONAIS EM HOSPITAIS DE PEQUENO PORTE BRASILEIROS}

\author{
Work and employment relations in small Brazilian hospitals \\ Vínculos profesionales en hospitales brasileños de pequeño porte
}

\begin{abstract}
RESUMO
Este estudo descreve os vínculos profissionais a partir de pesquisa em 3.524 hospitais de pequeno porte (HPP) brasileiros definidos na faixa de o a 50 leitos. Realizado in loco por meio de survey, teve como resultado relevante, além de criar base de dados até então inexistente, fornecer evidências para caracterizar essas instituições. Os principais resultados encontrados demonstram diferentes vínculos profissionais sendo utilizados nos contratos de trabalho, com maior ênfase nos vínculos estatutário, Consolidação das Leis Trabalhistas (CLT) e autônomos, e não sugerem diferenças quanto ao perfil de atenção e/ou aspectos gerais de estrutura e funcionamento. 0 vínculo profissional, mesmo refletindo uma situação contextual de origens estruturais nos novos rearranjos do mundo do trabalho e emprego, não permite conclusões definitivas acerca de seu impacto no cotidiano da saúde, mas abre possibilidades de estudos futuros em sintonia com outras dimensões de análise.
\end{abstract}

PALAVRAS-CHAVE | Vínculos profissionais, recursos humanos, hospitais, saúde, Brasil.

\begin{abstract}
The present study describes the work and employment relations observed in a survey with 3,524 small hospitals (HPP) - i.e., hospitals with o-5o beds - in Brazil. It was conducted in loco and its relevant results were the creation of a groundbreaking database on the subject and evidence for characterizing these institutions. The main findings show various work and employment relations in use in work agreements, with a greater emphasis on statutory relationships, agreements regulated by the Consolidated Labor Laws (Consolidação das Leis Trabalhistas [CLT]), and self-employment. Findings do not suggest differences regarding the profile of attention and/or general aspects of structure and functioning. Although they reflect a context structurally originated from new rearrangements in the work and employment world, work and employment relations do not allow definite conclusions about their impact on healthcare's daily routine. However, it opens the possibility for future studies in line with other dimensions of analysis.
\end{abstract}

KEYWORDS / Work and employment relations, human resources, hospitals, health, Brazil.

\section{RESUMEN}

Este estudio describe los vínculos profesionales basado en una investigación efectuada en 3.524 hospitales de pequeño porte (HPP) brasileños, definidos en el rango de o a 50 lechos. La encuesta, realizada in situ, además de crear una base de datos hasta entonces inexistente, tuvo como resultado relevante la obtención de evidencias para caracterizar esas instituciones. Los principales resultados demuestran diferentes vínculos profesionales utilizados en los contratos de trabajo, con mayor énfasis en los vínculos estatutarios, Consolidación de las Leyes Laborales (Consolidação das Leis Trabalhistas [CLT]) y autónomos, y no sugieren diferencias en cuanto al perfil de atención y/o aspectos generales de estructura y funcionamiento. El vínculo profesional, aunque refleje una situación contextual de orígenes estructurales en los nuevos reordenamientos del mundo laboral, no permite conclusiones definitivas a cerca de su impacto en el día a día de la salud, pero abre posibilidades para estudios futuros en sintonía con otras dimensiones de análisis.

PALABRAS CLAVE / Vínculos profesionales, recursos humanos, hospitales, salud, Brasil.

\section{ALLAN CLAUDIUS QUEIROZ BARBOSA \\ Professor da Universidade Federal de Minas Gerais, Faculdade de Ciências Econômicas - Belo Horizonte - MG, Brasil}




\section{INTRODUÇÃO}

Este artigo tem como objetivo central discutir a natureza dos vínculos profissionais em hospitais de pequeno porte (HPP) brasileiros. Partindo da ideia de que possíveis formas de contratação de pessoal podem sugerir uma lógica gerencial que torna a saúde mais ou menos efetiva em termos de uma ação voltada ao usuário, o vínculo é considerado genericamente como a maneira pela qual empregador e empregado estabelecem um contrato individual de trabalho, formalizado por meio de instrumento jurídico que determina as condições do trabalho.

O debate ganha relevância no espaço dos HPP considerando que esses hospitais possuem dinâmica peculiar, conforme apontou López (2004), pela sobrecarga nos prontossocorros, filas em prontos atendimentos e ambulatórios, falta de leitos nas unidades de terapia intensiva (UTI), demora na marcação de exames e acesso difícil a procedimentos cirúrgicos. Some-se a isso uma baixa resolubilidade da assistência e a não integração à rede.

López (2004) conceitua os HPP com base na definição adotada pela Organização Pan-Americana de Saúde (OPAS), em seu Estatuto da Organização Nacional de Acreditação, como estabelecimentos com, pelo menos, cinco leitos disponíveis para internação de pacientes, que garantam atendimento básico de diagnóstico e tratamento, possuindo equipe clínica organizada e assistência permanente de médicos. Segundo a mesma definição, um HPP exige a presença de serviço de enfermagem e atendimento terapêutico direto ao paciente durante 24 horas, com disponibilidade de serviços de laboratório e radiologia, serviços de cirurgia e/ou parto, bem como registros médicos organizados para observação e acompanhamento dos casos. Nesse contingente significativo de hospitais, as possíveis formas de contratação de pessoal existentes podem sugerir distintos arranjos, o que faz o debate sobre vínculo ganhar relevância, na medida em que, eventualmente, demonstra uma lógica gerencial que torna a saúde mais ou menos efetiva em termos de uma ação voltada ao usuário. Vínculo é a maneira pela qual empregador e empregado estabelecem um contrato individual de trabalho, formalizado por meio de instrumento jurídico que determina as condições do trabalho.

À luz dessa perspectiva, a referência adotada foi a Política Nacional de Atenção Hospitalar (PNHOSP) do Ministério da Saúde, que estabeleceu, em 2013, as diretrizes e normas para a organização do modelo da atenção hospitalar no Sistema Único de Saúde (SUS), acompanhada pela regulamentação das diretrizes operacionais da contratualização hospitalar. A PNHOSP teve como objetivo estabelecer diretrizes para a reorganização do componente hospitalar na rede de atenção à saúde, incluindo os hospitais com até 50 leitos. De acordo com o Cadastro Nacional de Estabelecimentos de Saúde (CNES), existiam, em setembro de 2013, 3.524 estabelecimentos públicos e privados com até 50 leitos, 2.724 deles oferecendo leitos ao SUS.

A estrutura do artigo apresenta, em seu primeiro momento, um referencial que associa recursos humanos, saúde e o vínculo como categoria de análise. Na sequência, são detalhados os procedimentos metodológicos do estudo, considerando o estado da arte dos estudos em hospitais e todo seu desenvolvimento, e apresentados os resultados gerais e sua análise.

\section{VÍNCULOS NO CONTEXTO DE RECURSOS HUMANOS E DA SAÚDE}

O debate sobre vínculos assume relevância no contexto da gestão de recursos humanos quando se observam as diferentes abordagens e perspectivas de estudo realizadas. Com efeito, Rondeau e Wagar (2002), por exemplo, visando entender melhor como as práticas de gestão de recursos humanos contribuem para o desempenho nas organizações de saúde submetidos a reduções de pessoal significativos, examinaram hospitais canadenses que sofriam processo de reestruturação.

Armstrong-Stassen e Schlosser (2010), analisando especificamente a categoria profissional de enfermagem, realizaram estudo longitudinal utilizando modelo para observar se as práticas de recursos humanos estariam ligadas à intenção de permanência desses profissionais no hospital. Os resultados demonstraram que a retenção desses profissionais, notadamente aqueles com idade mais avançada, requer práticas de recursos humanos específicas que sejam mais justas, e que o hospital valorize sua contribuição e preocupe-se com seu bem-estar.

Loan-Clarke, Arnold, Coombs, e Hartley (2010) discutiram, por outro lado, aspectos relacionados à retenção e rotatividade em estudo longitudinal de quatro profissões de saúde no sistema de saúde britânico. Os dados longitudinais revelaram a influência do contexto de trabalho em decisões de escolha de emprego.

Bach e Givan (2010), também na Inglaterra e procurando entender a agenda do governo do Reino Unido, por meio do incentivo a parcerias público-privadas para melhorar a prestação de serviços públicos, realizaram estudo de caso em um hospital e destacaram o grau de regulação das condições de emprego e seu impacto nas relações entre a força de trabalho e os sindicatos.

Townsend e Wilkinson (2010), por sua vez, observaram que reformas de saúde acontecidas nos últimos 25 anos, com foco na mudança estrutural, redução de custos e introdução de uma lógica de mercado, associadas à importância da gestão de recursos humanos, têm levado a pressões para eficiência 
e eficácia. Ao analisarem a importância e a complexidade da gestão de recursos humanos em hospitais em todo o mundo, concluíram ser cada vez mais importante compreender a forma como as pessoas são gerenciadas dentro dessas organizações.

Grimshaw, Rubery, e Marchington (2010) investigaram aspectos associados a recursos humanos em dois estudos de caso e identificaram três desafios comuns: como construir o comprometimento dos empregados e identidade na parceria sem colocar em risco os objetivos da organização; a necessidade em estabelecer carreiras atraentes em um contexto que requer algum grau de partilha de normas e coordenação da oferta de formação de competências; e como sustentar parcerias em ambiente de mudanças. Os resultados apontam, ainda, para problemas inerentes à gestão do emprego quando há mais de um vínculo profissional.

Chaisiri (1997), por sua vez, ao estudar o desenvolvimento de recursos humanos, analisou um hospital na Tailândia de 320 leitos e observou aspectos relacionados à satisfação dos pacientes em diferentes perspectivas. Tabibi, Vatankhah, Nasiripour, Vahdat, e Hessam (2011) também abordaram o desenvolvimento de recursos humanos como fundamental para educar uma força de trabalho qualificada e eficiente por meio da observação de um conjunto de 65 hospitais iranianos.

Analisando hospitais australianos, Khatri, Wells, McKune, e Brewer (2006) destacaram a importância do fator humano no cuidado à saúde e examinaram a gestão de recursos humanos em um hospital universitário e outro comunitário, indicando diferenças entre ambos.

El-Jardali, Tchaghchagian, e Jamal (2009) analisaram 61 hospitais libaneses, destacando que práticas de gestão são essenciais para a retenção de profissionais em hospitais, indicando o protagonismo dos gestores de recursos humanos em hospitais. Ao avaliarem sua percepção sobre os desafios que enfrentam e as estratégias atuais que estão sendo adotadas, os autores concluíram pela necessidade de um quadro de gerentes competentes para melhorar continuamente o status de funcionários em suas organizações. Ainda apontaram que os resultados do estudo podem se estender a outros países na região do Mediterrâneo Oriental.

Nessa linha de estudos que analisam recursos humanos em hospitais, Gupta e Dal-Poz (2009) observaram que avaliações de unidades de saúde têm sido cada vez mais utilizadas para medir e monitorar indicadores de desempenho do pessoal de saúde. Entretanto, a base de evidências global permanece ainda insuficiente. Em parte, isso seria devido à grande variabilidade nos métodos e instrumentos de avaliação, o que dificultaria a comparabilidade entre e dentro dos países e ao longo do tempo. A partir de estudo coordenado pela Organização Mundial da Saúde (OMS) em seis países (Chade, Costa do Marfim, Jamaica, Moçambique, Sri Lanka e Zimbábue), suas conclusões sugerem que estudos dessa natureza podem auxiliar os países no desenvolvimento de maior capacidade para identificar e medir indicadores de desempenho e, eventualmente, contribuir para melhor compreensão da dinâmica de pessoal de saúde.

LaForgia e Coutolenc (2009), ao analisarem o sistema hospitalar brasileiro, destacam sua centralidade no sistema de saúde brasileiro indicando um gasto público em torno de $70 \%$ do orçamento da saúde. Os autores discutem mecanismos e formas de melhorar a assistência hospitalar no Brasil e destacam, como pontos fortes sobre recursos humanos, o estímulo à "estabilidade de pessoal e a proteção contra interferência política; estímulo à contratação de um núcleo de servidores públicos especializados em bens públicos" (pp. 285-286).

Como pontos fracos, os autores destacam a incapacidade de seleção pelos gerentes dos candidatos, além de que "todos os funcionários de determinada categoria técnica recebem o mesmo salário inicial; os aumentos salariais são feitos globalmente, definidos pelo Governo e válidos para todos os funcionários; emprego vitalício garantido após três anos de experiência; o processo de demissão é longo e tortuoso; a contratação está sujeita a concursos públicos para vagas nos serviços públicos" (LaForgia \& Coutolenc, 2009, p. 286), e o sistema não proporciona uma avaliação dos resultados. A partir dos dados do Instituto Brasileiro de Geografia e Estatística (IBGE, 2003) recolhidos em 7.397 hospitais, os autores apontam que mais de $60 \%$ deles possuem entre zero e 49 leitos. O IBGE baseia a medição de hospitais em seu número de leitos.

Em contrapartida a esses estudos, embora historicamente a discussão sobre recursos humanos na saúde no Brasil tenha seus primórdios na década de 1970 (Paim, 1994), Vieira (2005) chama atenção para o caráter fragmentado e limitado desse debate na implementação e posterior consolidação do SUS. Somente em 1986, na esfera pública, com a realização da Primeira Conferência Nacional de Recursos Humanos em Saúde, foram discutidos temas como remuneração, condições de trabalho e incentivos para a qualificação, estando aspectos mais concretos associados à formação profissional. Na Segunda Conferência Nacional de Recursos Humanos em Saúde (1993), Pierantoni, Varela e França (2004) observaram que o debate se fez em torno do desempenho e produtividade, trazendo consigo novos temas, tais como vínculos profissionais, diferentes formas de remuneração e regulamentação do mercado de trabalho. Some-se a isso diferentes cargas de trabalho, fixação de profissionais e regulamentação formal sobre as profissões, além da concentração de pessoal nos grandes centros urbanos (OPAS, 2001) e ausência 
de procedimentos clássicos em recursos humanos (promoção, relações de trabalho flexíveis, entre outros).

No que se refere ao caso específico sobre vínculos, Seixas (2006) afirma que a precarização do trabalho e a consequente perda de garantias trabalhistas acontecem no setor público, sendo consideradas fatores de desgaste no trabalho, gerando uma relação instável aos profissionais. A esse debate, Nogueira (2002) acrescenta, ainda, arranjos e modalidades como a terceirização, a parceria com instituições não lucrativas, cooperativas de trabalho e contratos por tempo determinado acertados diretamente com os profissionais como complicadores desse quadro.

Em meio a essa complexidade, aproximar as dimensões clássicas do debate sobre recursos humanos do ambiente da saúde exige contemplar variáveis e indicadores que ampliem o olhar. Ou seja, a abordagem de recursos humanos envolve aspectos objetivos, baseados em processos técnicos e subjetivos, que dizem respeito à relação que as pessoas estabelecem com o próprio trabalho (Silva, Rodrigues, Rocha, \& Rodrigues, 2009). Isso pode ser corroborado por Fleury (2011), que demonstra, no âmbito do SUS, um desenho de governança e estrutura de processos e de tomada de decisão onde não há hierarquia entre União, estados e municípios, mas competências para cada um desses três gestores do SUS. Embora o vínculo possa ser genericamente definido como a relação entre empregador e empregado, estabelecida por meio de acordo ou contrato com diferentes nuances e naturezas, dependendo da forma do instrumento jurídico celebrado entre as partes, ele pode assumir perspectivas e expressões distintas.

Um primeiro recorte diferencia duas categorias, estáveis e não estáveis. O vínculo estável refere-se aos profissionais denominados estatutários, isto é, aqueles que possuem vínculos nos quais existem regras que regulamentam a relação entre empregado, no caso, servidor público, e seu contratante, o Estado; celetistas (tipo de vínculo no qual o empregado é regido pela CLT, sendo a relação jurídica de natureza contratual celebrada pelo contrato de trabalho), em emprego público, isto é, indicando serviço não eventual ao Estado e às entidades da administração pública direta ou indireta, que dependem de aprovação em processo seletivo público; e profissionais reunidos em cooperativas ou residência. 0 vínculo não estável diz respeito a contratos de trabalho temporários, autônomos ou cargos comissionados que não apresentam relação formal de emprego, e o serviço prestado é eventual ou não permanente.

Essa situação evidencia mecanismos nas relações entre profissionais e organizações, que se expressam, muitas vezes, em formas precárias de emprego. A precarização é entendida como qualquer situação em que os profissionais têm vínculos não estáveis ou irregulares (formais ou não) com perda das garantias sociais, em função de novos arranjos e modalidades, adotados pela gestão, incluindo a terceirização, a parceria com instituições não lucrativas, cooperativas de trabalho e, ainda, contratos por tempo determinado negociados diretamente com os profissionais.

No caso da administração pública brasileira, Nogueira, Baraldi, e Rodrigues (2004) reconhecem duas perspectivas: por meio dos vínculos estabelecidos por uma pessoa com a administração pública, ou seja, admissão e contratação de trabalhadores por esse setor; e por meio dos vínculos indiretos estabelecidos por mediação de uma entidade privada qualquer, ou seja, os contratos de terceirização. Nas duas situações, podem ocorrer contratos precários, retirando garantias legais e proteção social (Nogueira et al., 2004).

Ainda no âmbito da gestão pública, os limites impostos aos gastos com pessoal nas três esferas de governo por meio da Lei n. 8.112/90, que regulamenta o Regime Jurídico Único dos Servidores Públicos Federais, dificultam a contratação de profissionais necessária à expansão das ações e dos serviços de saúde e a remuneração em níveis compatíveis ao mercado. Isso acaba por favorecer a diversificação das formas de contratação, vinculação e remuneração de profissionais nos serviços públicos de saúde.

Nessa perspectiva, visando assegurar a expansão ou mesmo o funcionamento dos serviços, tornou-se usual incorporar aos mecanismos de seleção por concurso e de carreira pública outras formas de contratação e remuneração, tais como contratações via CLT, diretas ou por meio de convênios com outras instituições, contratações temporárias, remuneração por prestação de serviços, incentivos salariais ou contratação de cooperativas de profissionais de saúde (Conselho Nacional de Secretários Estaduais de Saúde [Conass], 2004).

Essa questão, em grande medida, joga luz sobre a relevância do vínculo como fator fixador, pois, ao se pensar em um modelo que assegure a continuidade do atendimento, seria imprescindivel que houvesse efetivamente o acompanhamento por parte dos profissionais envolvidos na saúde, o que pode ser dificultado quando as alternativas encontradas pela gestão passam por contratos instáveis e com tempo determinado.

Soma-se a isso o fato de que o vínculo, além dos aspectos mencionados, evidencia questões que ultrapassam o regime de contratação e a forma de seleção, tais como a descontinuidade administrativa e as condições de infraestrutura e suporte que os municípios têm (ou não) a oferecer aos profissionais que, eventualmente, pretendem trabalhar nesses locais. Essas práticas, amplamente conhecidas, dificultam o desenvolvimento de ferramentas e/ou ações específicas de recursos humanos. 


\section{METODOLOGIA DO ESTUDO}

Este artigo foi realizado a partir de dados gerais coletados por Facchini e Barbosa (2014) em levantamento nacional por meio de survey in loco de todos os HPP brasileiros, caracterizando-se como estudo censitário. Essa população reúne todos os casos que se conformam às especificações de pequeno porte (Selltiz, Jahoda, Deutsch, Cook, 1974), isto é, o universo de unidades (Bryman \& Bell, 2011). A realização do estudo aconteceu pela ausência de bases de dados capazes de gerar evidências para caracterizar essas instituições em termos de estrutura física, de processos de saúde e gerenciais e de processos de trabalho.

Foram adotados, como ponto de partida do percurso metodológico, a caracterização dos HPP quanto ao porte; o levantamento do universo dos estabelecimentos hospitalares desse porte e perfil; o levantamento de dados secundários no CNES, Sistema de Informação Ambulatorial (SIA) e Sistema de Informações Hospitalares (SIH) sobre esses estabelecimentos hospitalares; a identificação e definição das dimensões de análise; a definição das dimensões e variáveis para composição; e a definição do instrumento de coleta de dados utilizado no conjunto dos hospitais pesquisados. Isso permitiu retirar o substrato sobre vínculos profissionais e recursos humanos.

$\mathrm{Na}$ caracterização dos HPP quanto ao porte, o estudo adotou orientação tomada em reunião da Comissão Intergestora Tripartite (CIT), realizada no dia 26 de setembro de $2013 \mathrm{em}$ Brasília, onde foi estabelecida a PNHOSP. Essa comissão é um espaço intergovernamental político e técnico em que ocorrem o planejamento, a negociação e a implementação das políticas de saúde pública, constituída no nível federal por representantes do Ministério da Saúde (MS), Conass e Conselho Nacional de Secretarias Municipais de Saúde (Conasems). A representação de estados e municípios é regional, sendo um representante para cada uma das cinco regiões do País.

Nessa reunião, foi definido que os HPP seriam aqueles na faixa de o a 50 leitos. Assim, de acordo com o CNES, existiam, em 2014, 3.524 estabelecimentos, públicos e privados, com até 50 leitos.

O levantamento de dados secundários no CNES, SIH e SAl sobre esses estabelecimentos hospitalares permitiu balizar e complementar o seu perfil e contribuiu para análise posterior dos resultados relacionados aos vínculos profissionais. Para isso, foram identificados: 1) distribuição espacial (localização) dos HPP; 2) porte considerando diferentes faixas até 50 leitos; 3) esfera administrativa (municipal, estadual, federal e privado); 4) natureza jurídica por região do País; 5 ) hospitais que possuem leitos SUS; 6) modalidade de gestão dos hospitais (se é realizada pelos municípios, pelos estados ou compartilhada); 7) tipo de atendimento prestado; 8) existência de bloco cirúrgico; 9) existência de centro obstétrico; e 10) existência de serviço de apoio diagnóstico.

A elaboração, identificação e definição das dimensões de análise tiveram como base a definição das seguintes dimensões, adaptadas de Veillard et al. (2005): infraestrutura (existência de dados selecionados da base CNES referentes aos aspectos jurídicos/legais, físicos, equipamentos, administrativos); assistência (variáveis indicativas da presença de ambulatórios, urgência, internação, serviços de apoio diagnósticos, leitos, clínicas, especialidades, regulação assistencial, presença de profissionais, turnos de trabalho e outros que caracterizem a assistência prestada, origem da clientela e dados de ocupação de leitos); recursos humanos (categorias profissionais existentes, tipos de contrato informado, carga horária e outros quesitos a partir do perfil profissional do estabelecimento e informado no CNES); financiamento (fontes regulares e extraordinárias de financiamentos de origem municipal, estadual e federal, bem como os dados referentes às despesas de cada instituição); qualidade e segurança do paciente (verificação da qualificação profissional, estratégias e planos de ação visando à qualidade da atenção prestada e a segurança do paciente); responsabilidades na rede de atenção à saúde local-regional (responsabilidades junto aos serviços locais-regionais, inclusive relação com os gestores, instrumento, relação com regulação municipal/estadual, Conselho de Saúde e outros); e desempenho (parâmetros de desempenho junto aos HPP visando à realização de comparações entre os diferentes contextos).

Isso permitiu a definição do instrumento de coleta de dados utilizado no conjunto dos hospitais pesquisados. Esse instrumento foi aplicado em todos os hospitais indicados no universo, por meio de respostas autodeclaradas junto a pelo menos um dos membros do corpo diretivo previamente identificado (diretor clínico, diretor-geral e chefe da enfermagem), com o tempo de resposta variando em função da maior ou menor facilidade dos respondentes em obter e possuir as informações solicitadas.

O instrumento elaborado possuía 16 grandes blocos, totalizando 2.014 variáveis assim distribuídas: 1) identificação do respondente (dados gerais); 2) identificação da instituição pesquisada; 3) identificação da instituição mantenedora; 4) informações gerais do hospital (organização da gestão, apuração de indicadores; existência de dispositivos de humanização; informações constantes no prontuário, canais de comunicação, mecanismos de aferição da satisfação dos usuários, incentivos à certificação de qualidade, visitas); 5) informações de infraestrutura predial (edificação, adequação, acessibilidade, estacionamento, descrição de equipamentos, leitos, instalações diversas para 
atendimento e oferta de serviços de saúde, análises clínicas); 6) tecnologia de informação (infraestrutura, equipamentos, sistemas institucionais de informação, programação de ações de supervisão hospitalar); 7) segurança do paciente (ações e infecções relacionadas à assistência); 8) inserção do hospital na rede de atenção à saúde (redes temáticas, desenvolvimento de ações, regulação, pactualização, plano diretor hospitalar, conselhos assistenciais); 9) unidade de urgência (atendimento, regime de funcionamento, atendimento de demandas); 10) unidades ambulatoriais (especialidades médicas); 11) unidades de internação (processo de trabalho); 12) unidades de bloco cirúrgico; 13) unidades de apoio diagnóstico e terapêutico (serviço de imagem, farmácia, nutrição, lavanderia, manutenção predial); 14) ensino e pesquisa (existência de programas de residência, estágios, educação permanente, pesquisa); 15) informações econômico-financeiras (receitas, benefícios ou subsídios, recursos para investimentos, dívidas, despesas gerais e com folha de pagamentos); e 16) gestão de recursos humanos (treinamento e desenvolvimento, desempenho, indicadores, dados gerais de pessoal, práticas, custo das ações, regime de contratação, despesas com pessoal, orçamento).

Nesse último bloco, constava o conjunto de aspectos diretamente associados à discussão de vínculos profissionais, que puderam ser cotejados com os demais considerando a natureza das atividades vis a vis as especificidades e exigências inerentes à prática da saúde quanto aos processo de trabalho e perfil de atendimento prestado, por exemplo.

$\mathrm{Na}$ coleta de dados, foram realizados procedimentos de recrutamento, seleção e treinamento de pesquisadores, facilitadores logísticos, supervisores, bem como de preparação do campo. Essa parte envolveu a estruturação de um sistema de acompanhamento da coleta de dados.

Foi elaborado sistema on-line de coleta de dados por meio de tablets que continham o instrumento para coleta eletrônica. Essa coleta realizou a checagem preliminar das informações e, após serem validadas, seu envio foi feito diretamente à base de dados, onde foram novamente avaliados por meio de parametrização eletrônica. Os dados aprovados em sua consistência foram computados para fins de controle de produtividade. Os dados que não atingiram os padrões estipulados foram reencaminhados para checagem, que envolveu desde o novo contato com o estabelecimento cujos dados não atendessem aos padrões necessários até a abordagem do pesquisador para esclarecimento de algum especificidade do estabelecimento visitado. Ou seja, a realização de coleta eletrônica de dados permitiu que, no momento da sua realização, houvesse validação dos dados, de modo a evitar a entrada de dados não condizentes com o estudo. A estruturação logística da coleta de dados, em função de sua extensão e complexidade, foi distribuída entre janeiro e novembro de 2014. Simultaneamente a isso, os dados obtidos nas bases existentes foram coletados em consonância para garantir compatibilidade temporal.

O Quadro 1 sistematiza o percurso metodológico.

\section{Quadro 1. Síntese metodológica}

\begin{tabular}{l|l}
\hline & Descrição geral \\
\hline Objeto de pesquisa & $\begin{array}{l}\text { Vínculos profissionais considerando } \\
\text { o escopo da tese }\end{array}$ \\
\hline Natureza da pesquisa & Quantitativa \\
\hline Método de pesquisa & Survey de caráter censitário \\
\hline Unidade de análise & Hospitais de pequeno porte \\
\hline Universo & $\begin{array}{l}\text { 3.524 hospitais de pequeno porte } \\
\text { brasileiros }\end{array}$ \\
\hline Coleta de dados & $\begin{array}{l}\text { Questionário estruturado aplicado in } \\
\text { loco nos hospitais }\end{array}$ \\
\hline Fontes de referência & $\begin{array}{l}\text { Gestores, coordenadores e analistas } \\
\text { que atuam na interface entre as } \\
\text { categorias de análise previamente } \\
\text { identificados em cada HPP estudado }\end{array}$ \\
\hline
\end{tabular}

\section{RESULTADOS E DISCUSSÕES}

$\mathrm{Na}$ apresentação dos resultados, foram privilegiados aspectos gerais associados aos vínculos profissionais. Os resultados serão apresentados sem a discriminação por estado ou região geográfica, tendo em vista não ser objetivo diferenciar especificidades e/ ou regionalidades. À luz do percurso metodológico e dentro do que foi preconizado no desenho conceitual da pesquisa, os resultados deste item, relativos à base de dados do CNES previamente estudada, indicam que a distribuição dos HPP pelo País apresentou, segundo dados de coordenadas geográficas, uma concentração de estabelecimentos dessa natureza nas regiões Sul, Sudeste e Nordeste. Nas demais regiões, há um padrão pulverizado de estabelecimentos. A Figura 1 evidencia essa situação.

A distribuição dos HPP pelas regiões do País evidenciou que o Nordeste é aquela que concentra a maior parte dos estabelecimentos. As regiões Nordeste e Sudeste representam $63 \%$ dos HPP brasileiros, conforme Tabela 1 a seguir. 
Figura 1. Distribuição espacial dos hospitais de pequeno porte brasileiros (novembro 2013)

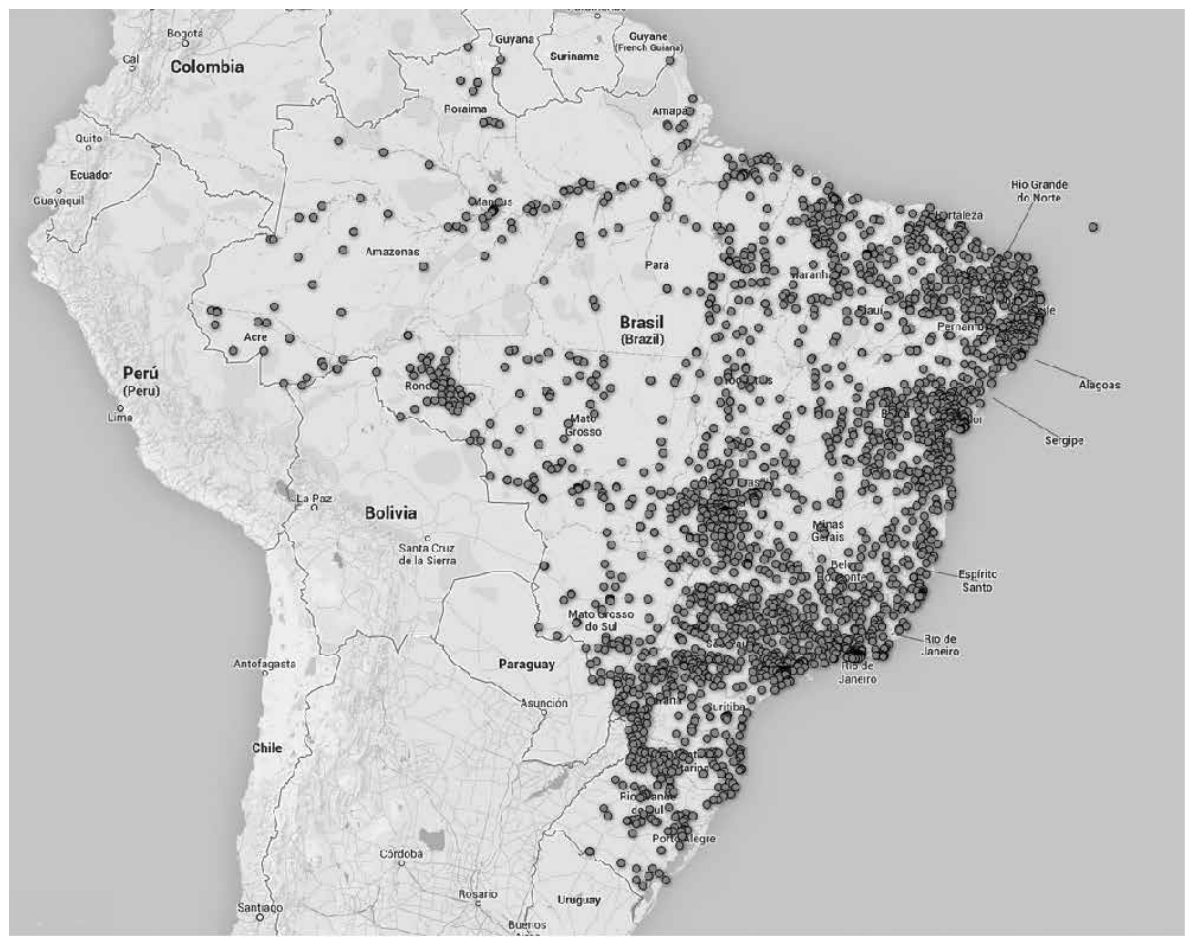

Fonte: Facchini \& Barbosa (2014).

Tabela 1. Quantidade de hospitais de pequeno porte no Brasil (setembro 2013)

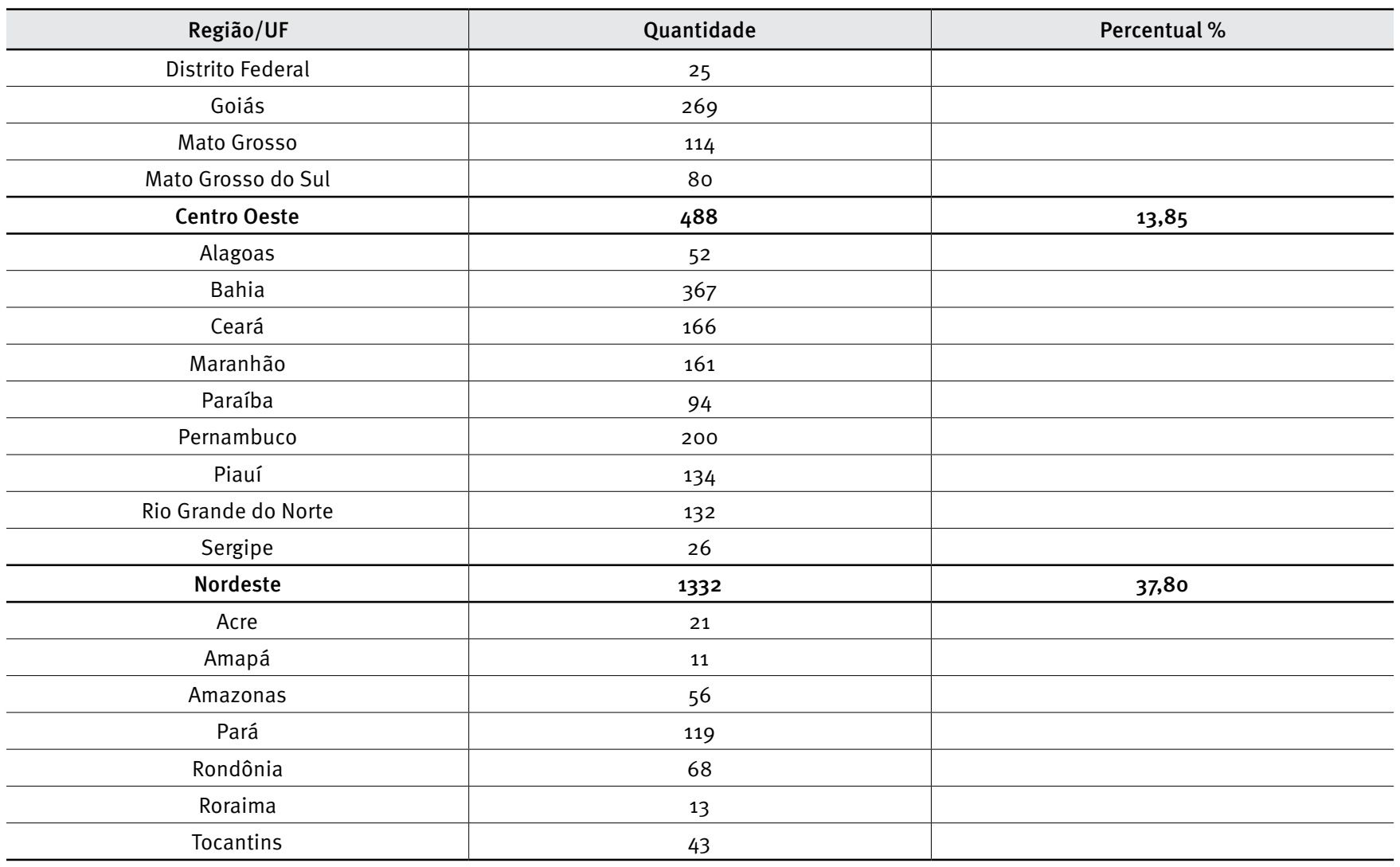


Tabela 1. Quantidade de hospitais de pequeno porte no Brasil (setembro 2013)

Conclusão

\begin{tabular}{c|c|c}
\hline Região/UF & Quantidade & Percentual \% \\
\hline Norte & 331 & $\mathbf{9 , 3 9}$ \\
\hline Espírito Santo & 49 & \\
\hline Minas Gerais & 334 & \\
\hline Rio de Janeiro & 190 & \\
\hline São Paulo & 324 & $\mathbf{2 5 , 4 5}$ \\
\hline Sudeste & $\mathbf{8 9 7}$ & \\
\hline Paraná & 247 & \\
\hline Rio Grande do Sul & 119 & \\
\hline Santa Catarina & 110 & $\mathbf{1 3 , 5 1}$ \\
\hline Sul & 476 & $\mathbf{1 0 0 , 0 0}$ \\
\hline Brasil & 3524 & \\
\hline
\end{tabular}

Fonte: Facchini \& Barbosa (2014).

A Tabela 2 mostra que a maioria dos HPP brasileiros tem entre 11 e 30 leitos, superando a metade do total.

Tabela 2. Porte dos hospitais de pequeno porte brasileiros

\begin{tabular}{|c|c|c|c|c|c|}
\hline & Menor que 10 leitos & Entre 11 e 20 leitos & Entre 21 e 30 leitos & Entre 31 e 40 leitos & Entre 41 e 50 leitos \\
\hline Distrito Federal & $36,00 \%$ & $16,00 \%$ & $40,00 \%$ & $4,00 \%$ & $4,00 \%$ \\
\hline Goiás & $10,04 \%$ & $33,83 \%$ & $26,77 \%$ & $16,73 \%$ & $12,64 \%$ \\
\hline Mato Grosso do Sul & $22,50 \%$ & $30,00 \%$ & $20,00 \%$ & $12,50 \%$ & $15,00 \%$ \\
\hline Centro Oeste & $13,11 \%$ & $31,15 \%$ & $27,46 \%$ & $15,57 \%$ & $12,70 \%$ \\
\hline Alagoas & $15,38 \%$ & $23,08 \%$ & $13,46 \%$ & $23,08 \%$ & $25,00 \%$ \\
\hline Ceará & $5,42 \%$ & $31,93 \%$ & $30,72 \%$ & $18,67 \%$ & $13,25 \%$ \\
\hline Maranhão & $6,21 \%$ & $26,09 \%$ & $29,81 \%$ & $22,98 \%$ & $14,91 \%$ \\
\hline Paraíba & $10,64 \%$ & $36,17 \%$ & $25,53 \%$ & $15,96 \%$ & $11,70 \%$ \\
\hline Pernambuco & $14,50 \%$ & $36,50 \%$ & $17,00 \%$ & $14,50 \%$ & $17,50 \%$ \\
\hline Piauí & $13,43 \%$ & $37,31 \%$ & $17,16 \%$ & $17,91 \%$ & $14,18 \%$ \\
\hline Acre & $19,05 \%$ & $38,10 \%$ & $19,05 \%$ & $14,29 \%$ & $9,52 \%$ \\
\hline Amapá & $9,09 \%$ & $27,27 \%$ & $18,18 \%$ & $27,27 \%$ & $18,18 \%$ \\
\hline Amazonas & $7,14 \%$ & $28,57 \%$ & $30,36 \%$ & $16,07 \%$ & $17,86 \%$ \\
\hline Pará & $5,88 \%$ & $16,81 \%$ & $35,29 \%$ & $18,49 \%$ & $23,53 \%$ \\
\hline Rondônia & $17,65 \%$ & $32,35 \%$ & $16,18 \%$ & $14,71 \%$ & $19,12 \%$ \\
\hline Roraima & $7,69 \%$ & $46,15 \%$ & $30,77 \%$ & $15,38 \%$ & $0,00 \%$ \\
\hline Tocantins & $34,88 \%$ & $13,95 \%$ & $27,91 \%$ & $11,63 \%$ & $11,63 \%$ \\
\hline Norte & $13,29 \%$ & $24,47 \%$ & $27,79 \%$ & $16,31 \%$ & $18,13 \%$ \\
\hline Espírito Santo & $12,24 \%$ & $18,37 \%$ & $32,65 \%$ & $12,24 \%$ & $24,49 \%$ \\
\hline Minas Gerais & $7,19 \%$ & $20,96 \%$ & $27,25 \%$ & $22,46 \%$ & $22,16 \%$ \\
\hline Brasil & $10,90 \%$ & $26,90 \%$ & $25,54 \%$ & $19,67 \%$ & $17,00 \%$ \\
\hline
\end{tabular}

Fonte: Facchini \& Barbosa (2014). 
Os HPP possuem, em sua maioria, gestão privada e municipal, com diferenças regionais. A região Nordeste, por exemplo, possui $66 \%$ dos hospitais vinculados aos municípios (Tabela 3 ).

Tabela 3. Esfera administrativa dos hospitais de pequeno porte (novembro 2013)

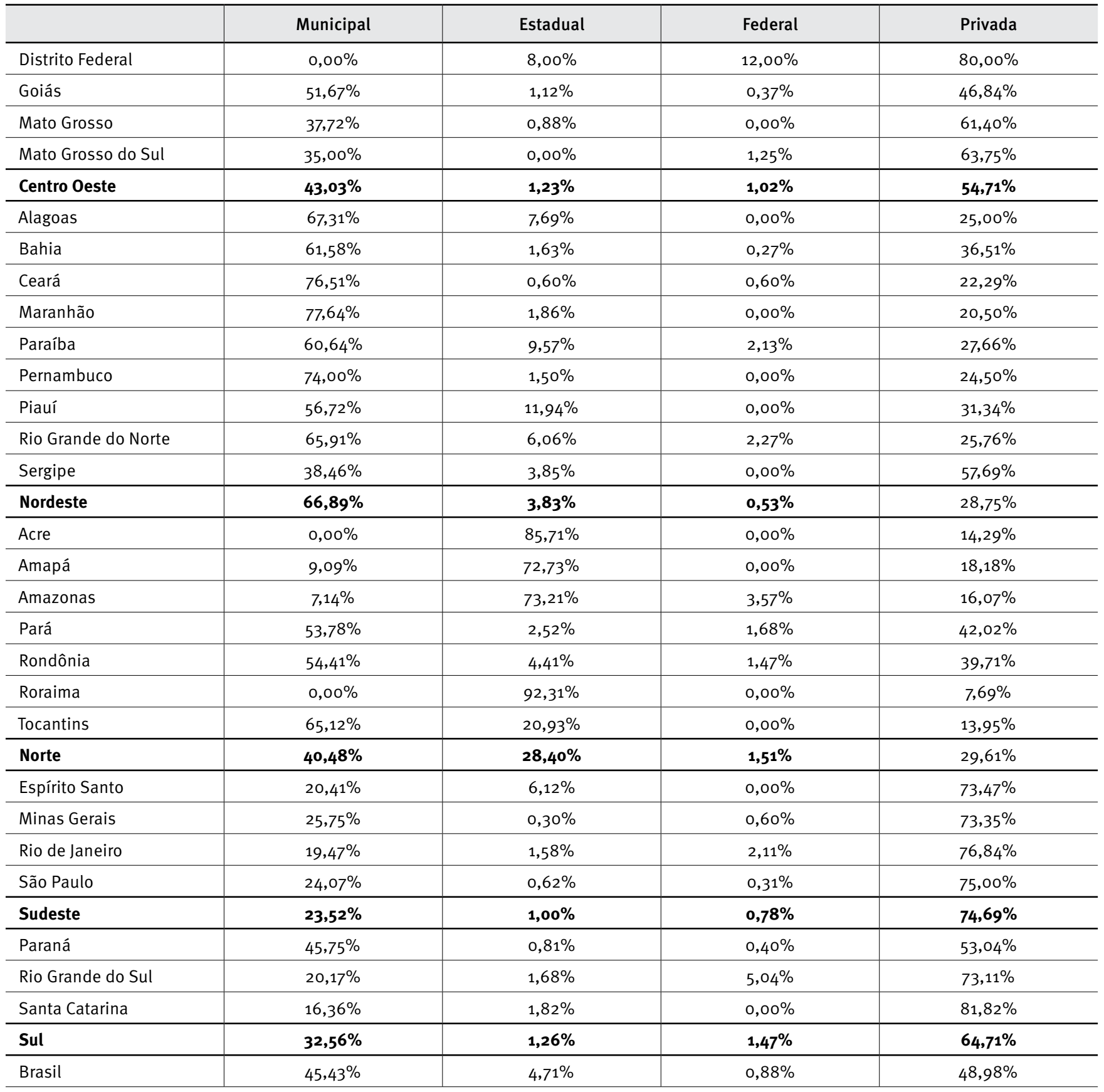

Fonte: Facchini \& Barbosa (2014).

Os resultados gerais podem ser sintetizados no Quadro 2 a seguir e evidenciaram um perfil com maior concentração em duas regiões do País, de reduzido porte em termos do número de leitos, gravitando majoritariamente entre a esfera privada e municipal, atendendo ao SUS, sem bloco cirúrgico e obstétrico e com apoio diagnóstico. É importante ressaltar a ausência de informação para mais de dois terços do total de hospitais pesquisados. 
Quadro 2. Perfil geral dos HPP a partir dos dados CNES

\begin{tabular}{l|l}
\hline Caracterização & Resultados majoritários \\
\hline Região de maior concentração geográfica & Nordeste e Sudeste \\
\hline Porte dos hospitais & Entre 11 e 3o leitos \\
\hline Esfera administrativa & Privados e municipais \\
\hline Natureza jurídica & Órgão públicos do poder executivo municipal \\
\hline Leitos & SUS \\
\hline Tipo de atendimento prestado & Atendimento contínuo 24 horas com plantão incluindo sábados, domingos e feriados \\
\hline Bloco cirúrgico & Não \\
\hline Centro obstétrico & Não \\
\hline Apoio diagnóstico & Sim \\
\hline
\end{tabular}

A caracterização encontrada no estudo pode ser sintetizada no Quadro 3 a seguir.

Quadro 3. Síntese da caracterização geral dos HPP estudados

\begin{tabular}{l|l}
\hline Participação no estudo & $78,8 \%$ aceitaram participar (2.777) \\
\hline Porte dos hospitais & Até 29 leitos $57 \%$ do total \\
\hline Natureza jurídica & $54,3 \%$ públicos municipais \\
\hline Atendimento ao SUS & $88,5 \%$ do total \\
\hline Tipo de atendimento prestado & Hospital geral com pronto atendimento \\
\hline Existência de aparelho mínimo de urgência e emergência & $49,9 \%$ possuem \\
\hline
\end{tabular}

O Quadro 4 a seguir apresenta uma síntese acerca da gestão de recursos humanos nos HPP estudados, sugerindo pistas sobre as práticas de recursos humanos. A primeira delas é que o número de hospitais que indicaram essas práticas é muito reduzido em termos do total de respostas válidas, girando em torno de $12 \%$.

A segunda pista é que o número médio de profissionais por HPP pode sugerir a necessidade do gerenciamento de pessoas, ou seja, um contingente acima de 45 pessoas em uma estrutura que conjuga assistência e gestão não deveria prescindir de tais mecanismos. Isso fica evidente quando se observa que existe uma lacuna na cobertura dessa assistência em termos de existência de médicos e enfermeiros em tempo integral, ficando maior quando ambos deveriam suprir essa lacuna. Ou seja, se a relação despesas de pessoal/despesas totais chega a quase dois terços, fica acima de $50 \%$ quando se considera somente o corpo médico.

Uma terceira pista demonstra a fragilidade de ações de recursos humanos pelo quase residual uso de indicadores convencionais (absenteísmo, rotatividade e horas de treinamento por empregado) nas práticas cotidianas. Ou seja, são poucos aqueles que informaram realizar tal acompanhamento, sendo menos ainda em se tratando de rotatividade. Esse aspecto suscita uma reflexão sobre as formas de vínculo profissional adotadas e a ausência de medições capazes de indicar parâmetros seguros aos gestores quanto à forma de atuar.

\section{Quadro 4. Síntese dos dados sobre gestão de recursos humanos nos HPP}

\begin{tabular}{l|c}
\hline Adoção de práticas de GRH & $7,6 \%$ \\
\hline Número de médicos (Média) & 9,8 por HPP \\
\hline Número de enfermeiros (Média) & 5,0 por HPP \\
\hline Número de profissionais de nível superior (Média) & 3,7 por HPP \\
\hline Número de profissionais de nível médio (Média) & 21,5 por HPP \\
\hline $\begin{array}{l}\text { Número de profissionais de apoio/administrativo de } \\
\text { nível superior (Média) }\end{array}$ & 2,1 por HPP \\
\hline $\begin{array}{l}\text { Número de profissionais de apoio/administrativo de } \\
\text { nível médio (Média) }\end{array}$ & 12,6 por HPP \\
\hline Número total de profissionais (Média) & 46,7 por HPP \\
\hline Existência de médico 24 horas/7 dias (\%) & $76,2 \%$ \\
\hline Existência de enfermeiro 24 horas/7 dias (\%) & $70,7 \%$ \\
\hline Existência de médico e enfermeiro 24 horas/7dias (\%) & $59,5 \%$ \\
\hline $\begin{array}{l}\text { Despesas de folha de pagamento/despesas totais } \\
\text { (Média) (\%) }\end{array}$ & $64,8 \%$ \\
\hline $\begin{array}{l}\text { Despesas de folha de médicos/despesas totais } \\
\text { (Média) (\%) }\end{array}$ & $53,4 \%$ \\
\hline Cálculo de indicadores de rotatividade (Média) (\%) & $1,94 \%$ \\
\hline Cálculo de indicadores de absenteísmo (Média) (\%) & $12,18 \%$ \\
\hline Número de profissionais por leito (Média) & 1,9 \\
\hline Despesa com treinamento (Média) (R\$) & $27.399,60$ \\
\hline Horas de treinamento por empregado (horas) & 2,9 \\
\hline
\end{tabular}


Os resultados encontrados sobre vínculos profissionais demonstram, pela Tabela 4, o vínculo predominante de cada hospital por natureza jurídica. Nesta tabela, todos os vínculos existentes foram agrupados em precários e não precários.

Tabela 4. Vínculos dos profissionais $\mathbf{x}$ perfil dos hospitais

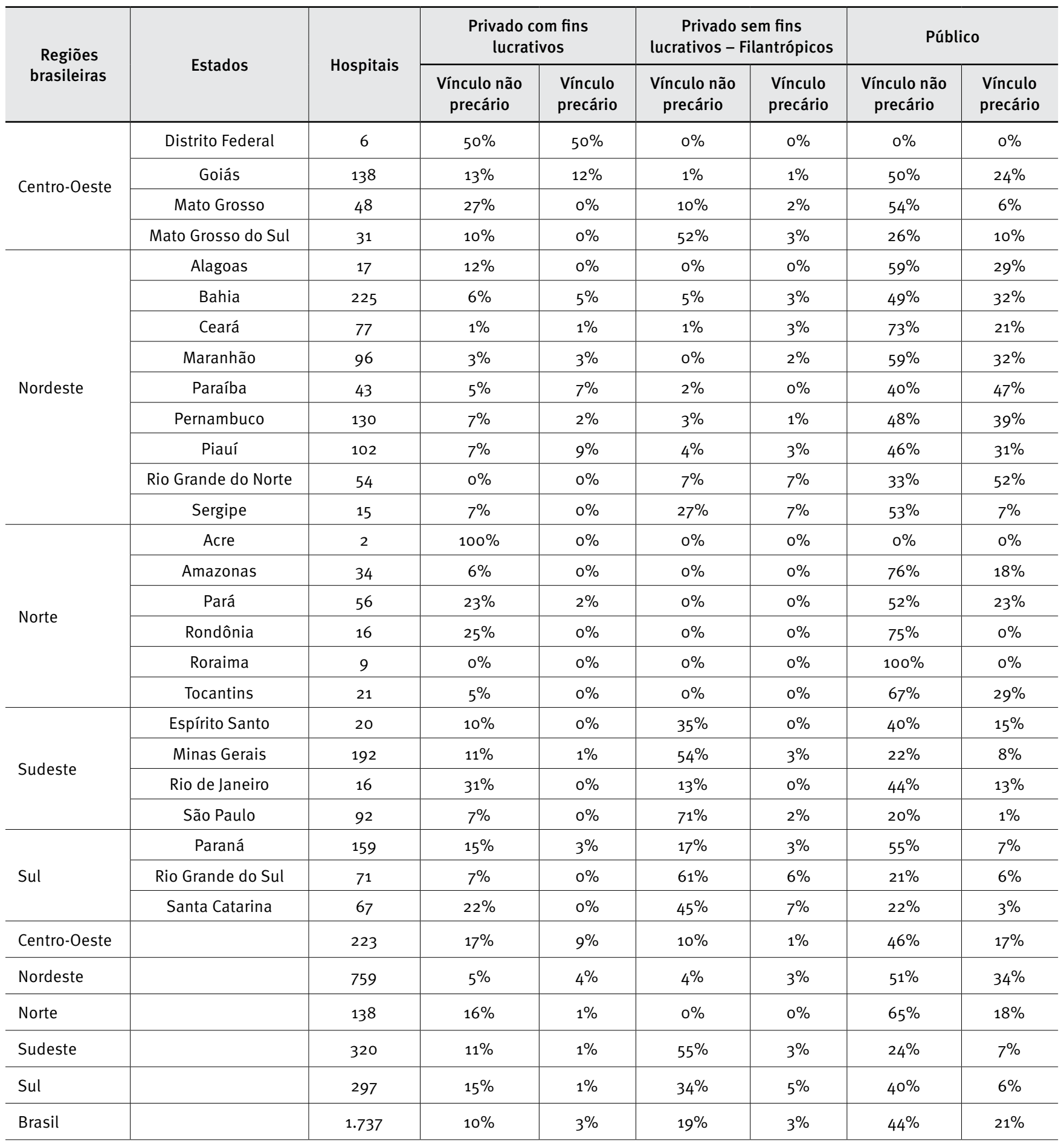

Nota: 0 total de HPP onde foi obtida a resposta chegou a 1.737.

Fonte: Elaborado a partir de Facchini \& Barbosa (2014).

O tipo de vínculo predominante é apresentado na Tabela 5. 
Tabela 5. Vínculo predominante nos HPP - \%

\begin{tabular}{|c|c|c|c|c|c|}
\hline \multirow[b]{2}{*}{ Vínculo predominante } & \multirow[b]{2}{*}{$\mathbf{N}$} & \multicolumn{3}{|c|}{ Percentuais (\%) } & \multirow[b]{2}{*}{$\%$} \\
\hline & & $\begin{array}{c}\text { HPP } \\
\text { públicos }\end{array}$ & $\begin{array}{c}\text { HPP privado com fins } \\
\text { lucrativos }\end{array}$ & HPP filantrópicos & \\
\hline Estatutário & 694 & $96 \%$ & $2 \%$ & $2 \%$ & 100 \\
\hline CLT & 584 & $18 \%$ & $28 \%$ & $54 \%$ & 100 \\
\hline Autônomos & 43 & $28 \%$ & $53 \%$ & $19 \%$ & 100 \\
\hline Contratos administrativos & 339 & $87 \%$ & $7 \%$ & $6 \%$ & 100 \\
\hline Cooperativa & 26 & $88 \%$ & $8 \%$ & $4 \%$ & 100 \\
\hline Contratação pessoa jurídica & 17 & $47 \%$ & $24 \%$ & $29 \%$ & 100 \\
\hline Terceirizados & 11 & $55 \%$ & $18 \%$ & $27 \%$ & 100 \\
\hline Sem vínculo formal & 23 & $65 \%$ & $13 \%$ & $22 \%$ & 100 \\
\hline Total & 1.737 & & & & \\
\hline
\end{tabular}

Fonte: Elaborado a partir de Facchini \& Barbosa (2014).

Os dados evidenciam que, nos hospitais públicos, a prevalência é de vínculos estatutários. Nestes, também predomina a utilização de contratos administrativos como forma de assegurar a relação profissional. Nos hospitais filantrópicos, a CLT surge como a mais significativa relação contratual, prevalecendo nos hospitais privados a relação em formato de autônomos.

Os resultados extraídos dos dados levantados demonstram, no caso dos vínculos, que o tipo de HPP define a forma de contratação mais usual, isto é, o recorte público e privado diferencia a prevalência dos vínculos. Em HPP públicos, contratos estatutários são majoritários, ao passo que, nos hospitais privados, existe a utilização do recurso de profissionais autônomos. Em contrapartida, os hospitais filantrópicos utilizam-se de mecanismos regulatórios típicos da CLT.

Com efeito, a estrutura dos hospitais, majoritariamente concentrados nas regiões Nordeste e Sudeste do País, com perfil entre 11 e 30 leitos, em sua maioria voltados à lógica do SUS, com atendimento contínuo e diário, mas com existência de aparelhos e urgência e emergência restrito a quase metade do total de HPP estudados, adota, em sua minoria, práticas de recursos humanos (naqueles hospitais que responderam a essa questão), mas consome quase dois terços de suas despesas com pessoal.

Quanto aos vínculos, o recorte entre estatutário, CLT e autônomo não sugere diferenças significativas quanto ao perfil de atenção e/ou aspectos gerais de estrutura e funcionamento. Ou seja, o vínculo profissional, mesmo refletindo uma situação contextual de origens estruturais nos novos rearranjos do mundo do trabalho e emprego, não permite conclusões definitivas acerca de seu impacto no cotidiano da saúde.

O que se sabe, e é muito debatido no contexto dos serviços, é que as controvérsias sobre situações de precariedade e/ou de efetividade têm efeitos não conclusivos sobre as práticas de recursos humanos, muitas vezes dependentes de recursos, legislação e orientações políticas.

\section{CONCLUSÕES}

Pelo estudo realizado e após análise descritiva dos dados, a dispersão por diferentes formas de vínculo, normalmente associado às maneiras adotadas pelos diferentes gestores para fazer frente às questões legais e de captação de profissionais, não permite ações homogêneas de recursos humanos, criando diferentes referências para o gerenciamento dos profissionais de saúde.

Essa discussão suscita muitas questões, sendo uma delas, por exemplo, associada ao seu gerenciamento no cotidiano hospitalar. Quando se discute contemporaneamente o tema da gerência, ela é tomada como um instrumento do processo de trabalho em saúde, voltado a um modelo assistencial centrado no usuário, capaz de ser protagonista de mudanças e compromissado com a defesa da vida, e não mais voltado ao controle dos procedimentos.

Nessa perspectiva, os serviços de saúde, de uma forma geral, e os HPP, em particular, estudados na dimensão dos vínculos 
profissionais, devem estar alicerçados no modelo clínico de atendimento e também em ferramentais e conceitos como aqueles que associam planejamento e o uso de dados epidemiológicos, dentro de uma lógica de integralidade das ações de saúde a indivíduos e grupos da comunidade. Esse perfil suscita também uma discussão sobre a busca de uma economia de escala quando os custos no longo prazo se reduzem com o aumento do volume de produção, conforme observou Posnett (2002).

Os resultados obtidos no estudo nacional demonstram que essa questão está longe de seguir aspectos técnicos ou modelos conceituais previamente definidos, estando sujeita a interferências exógenas à prática gerencial dotada de racionalidade intrínseca à gestão. Assim, os vínculos sugerem que as ações de recursos humanos atuam reativamente às necessidades de saúde, podendo ou não interferir na atenção ao usuário e à população.

A existência em maior ou menor grau de vínculos precários ou não precários sugere reflexões sobre qual das formas estaria mais propensa às respostas para questões de saúde, e, não sendo objeto da análise descritiva proposta nesta tese, abre a possibilidade e o desafio de conjugar variáveis sobre aspectos epidemiológicos e de saúde que podem indicar soluções às necessidade e demandas de saúde da população.

O debate sobre vínculos nos HPP pode ser também visto em outros níveis de atenção à saúde no Brasil e serve como reflexão sobre possíveis alternativas de carreira na saúde como um todo, pela sua relevância e impacto sobre o usuário. Ou seja, o debate sobre vínculos pode assumir relevância sobre a ação final na saúde, com diferentes nuances, pois, como bem observou Rodrigues (2008), não é possível determinar causas isoladas, e alguns estudos trabalham com a satisfação ou busca por formação profissional como motivadores para mobilidade dos médicos.

Os Gráficos 1 a 6 a seguir apresentam uma primeira reflexão relacionando vínculos com despesas de pessoal. Cada ponto em cada gráfico representa um hospital, podendo o hospital ter diversos profissionais em cada vínculo. Não foi intenção utilizar modelos de regressão nem análise de correlação (Pearson) ou pós-teste. Esses aspectos tiveram a intenção de somente refletir sobre novas possibilidades de análise no campo de recursos humanos em sua expressão nos vínculos profissionais.

Esses gráficos indicam se determinado vínculo possui relação com algum padrão de percentual de gasto para pagamento de pessoal, que considera o valor global dedicado ao pagamento das pessoas para o hospital em questão. Entretanto, a correlação em termos numéricos é baixa, embora não haja similitude comparativa em outros estudos dessa magnitude nesse grupo de hospitais, em consequência de os vínculos não serem mutuamente excludentes, isto é, um hospital pode ter profissionais em todas as categorias de vínculos, simultaneamente. Ainda, o percentual da folha de pagamento diante das despesas do hospital considera todos os vínculos, não somente aquele específico, e isso acaba por diminuir as correlações.

\section{Gráfico 1. Vínculo x percentual da folha com pessoal - estatutário federal}

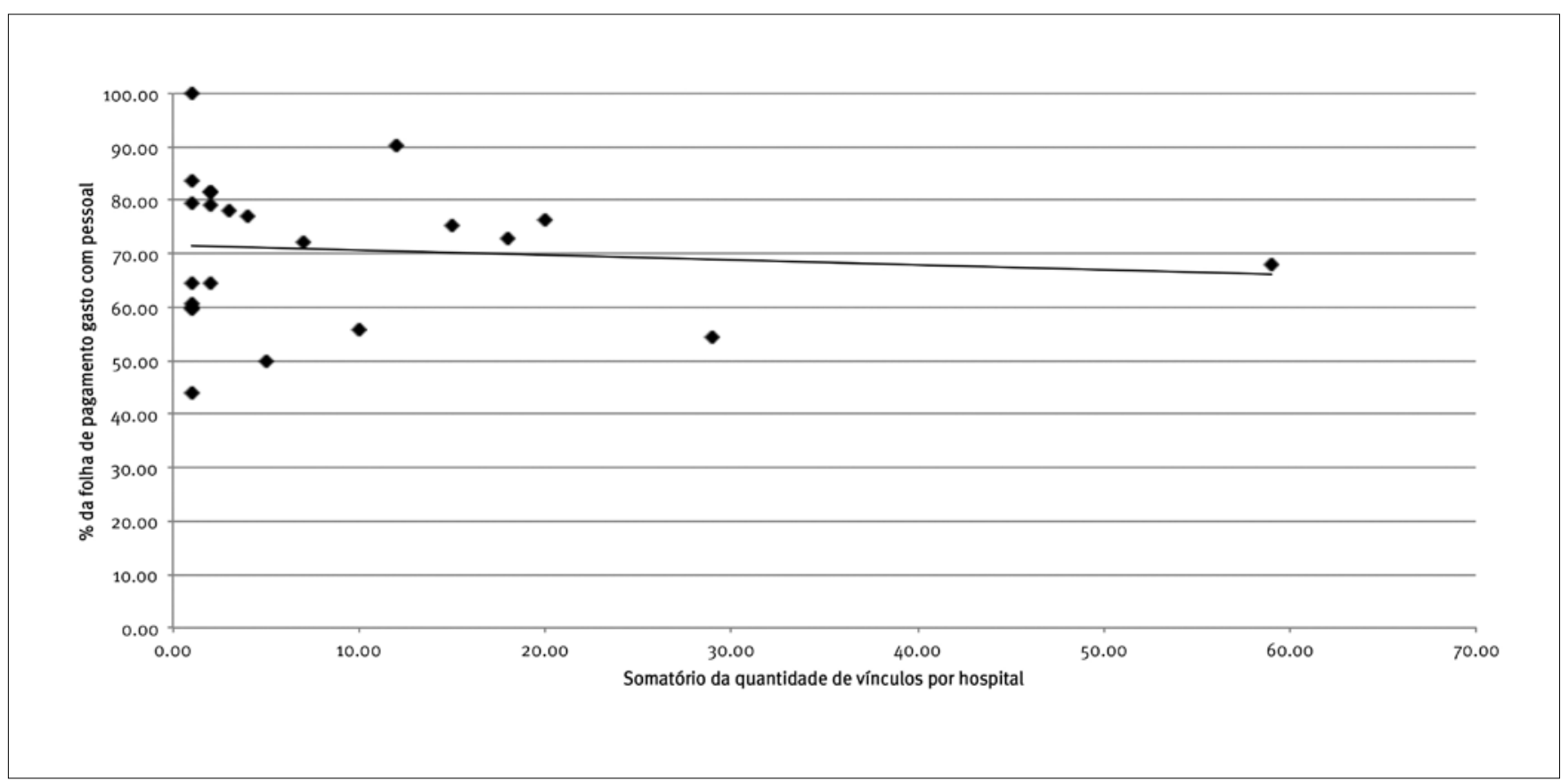


Gráfico 2. Vínculo x percentual da folha com pessoal - estatutário estadual

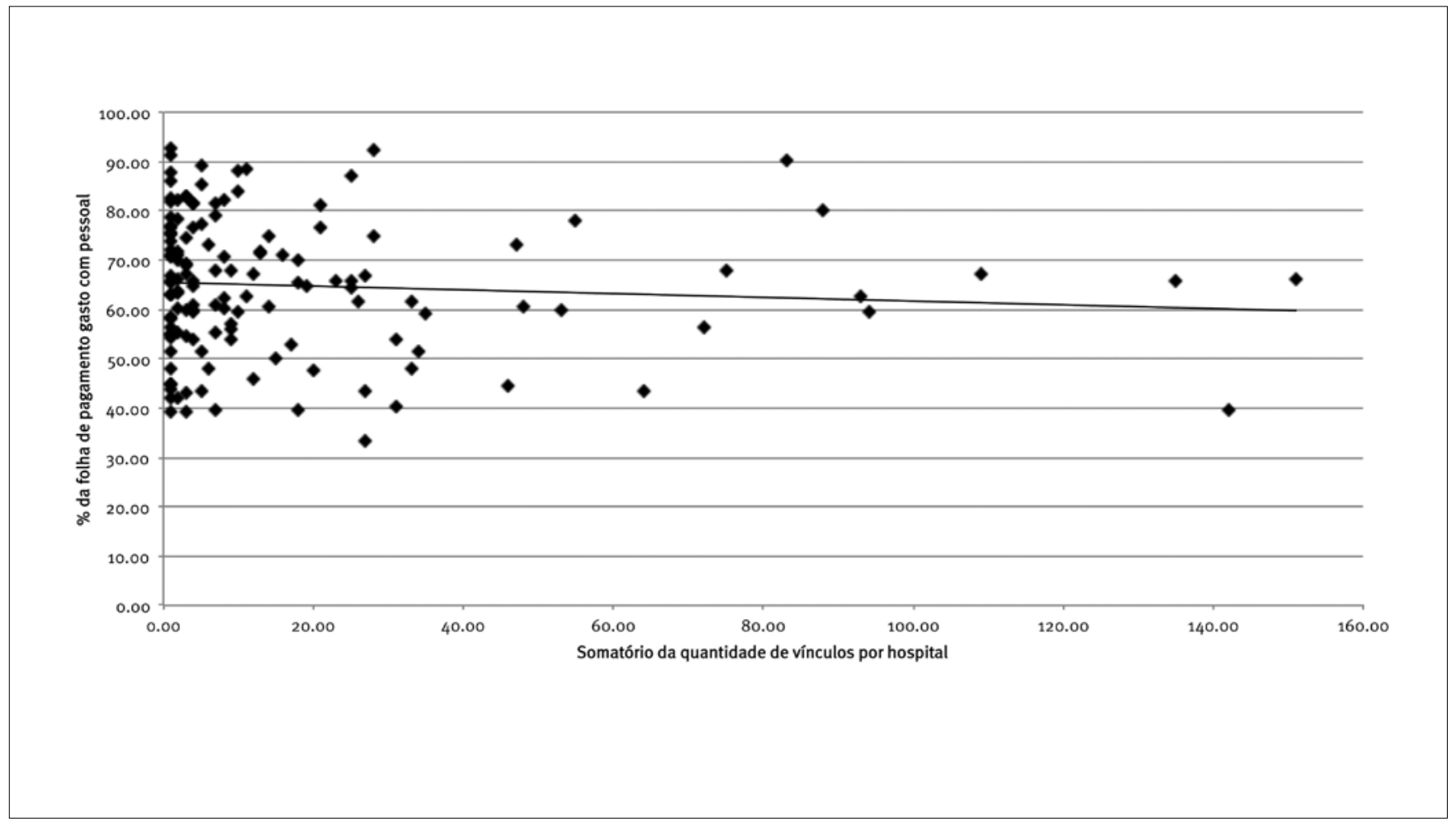

Gráfico 3. Vínculo x percentual da folha com pessoal - estatutário municipal

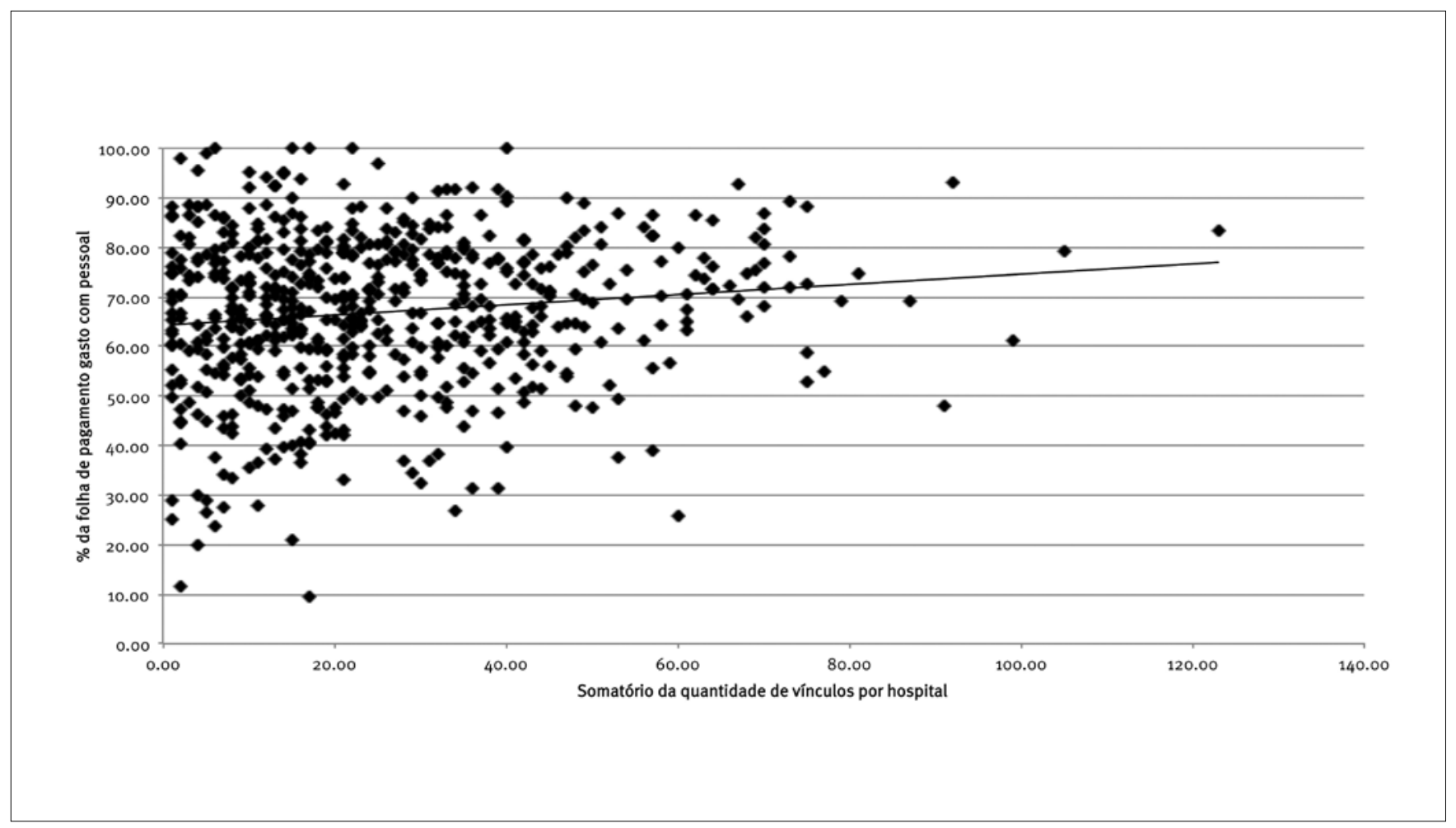


Gráfico 4. Vínculo x percentual da folha com pessoal - CLT

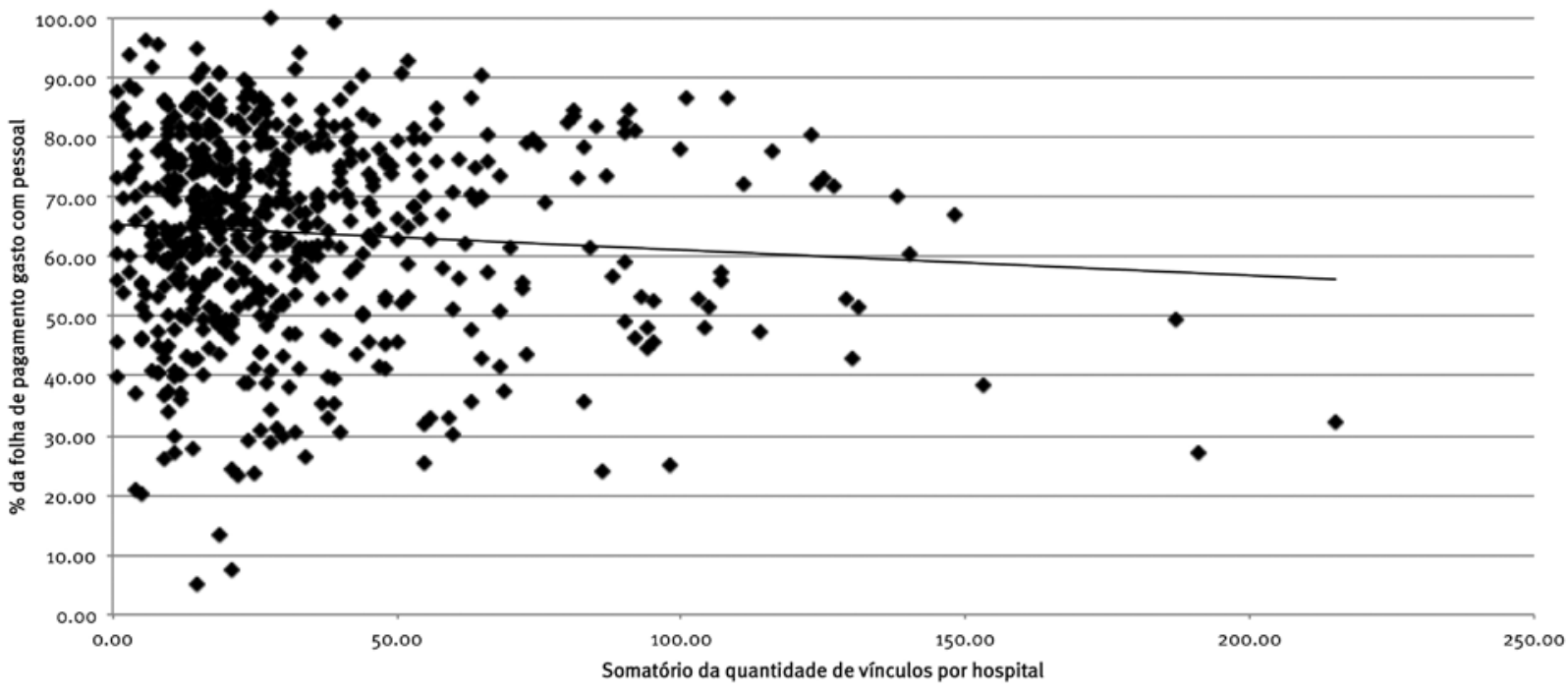

Gráfico 5. Vínculo $x$ percentual da folha com pessoal - terceirizados

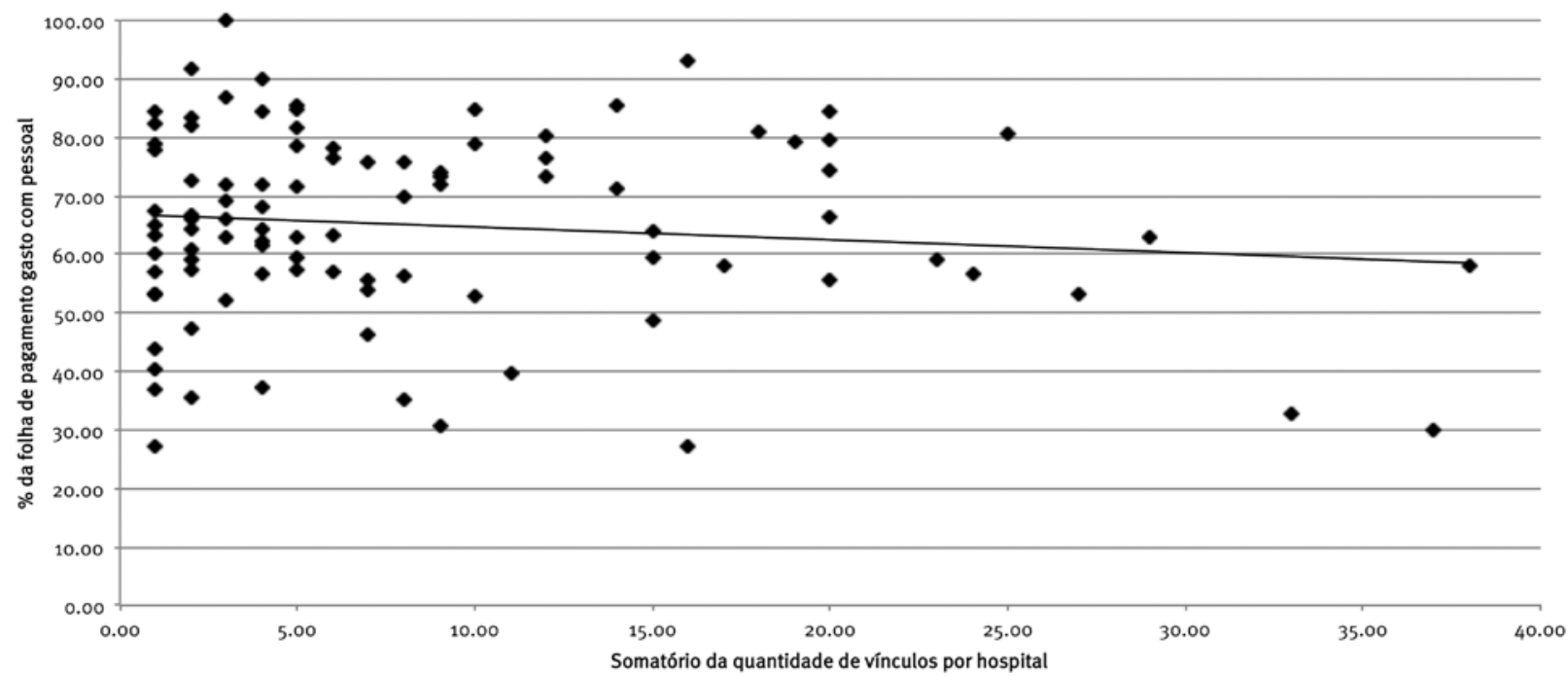


Gráfico 6. Vínculo x percentual da folha com pessoal -autônomos

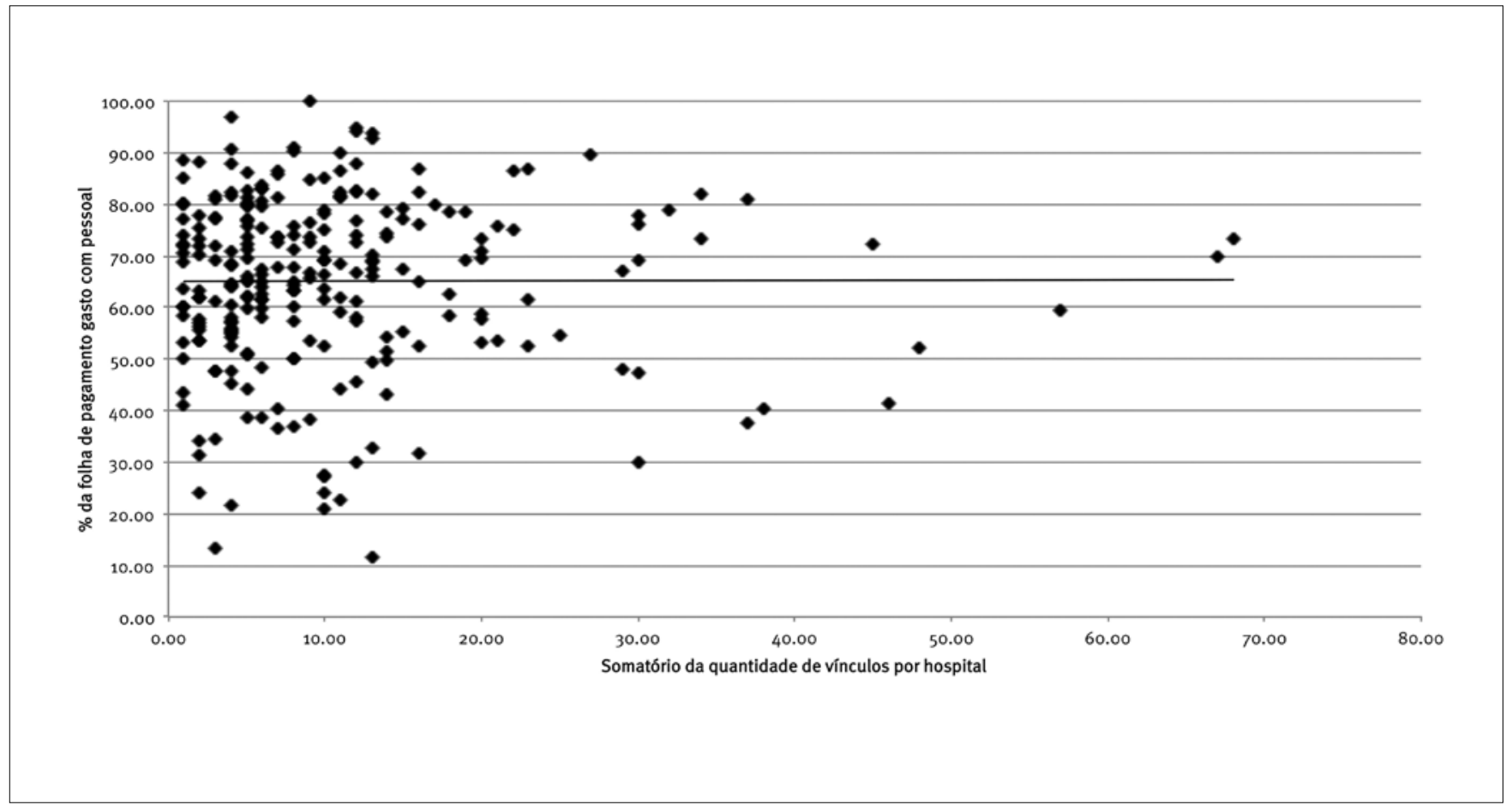

O Gráfico 7 demonstra que os HPP são hospitais com um número de profissionais que utiliza grande parte de seus recursos financeiros para pagamento de pessoal, tendo casos de uso integral de recursos financeiros para tal finalidade.

Gráfico 7. Somatório de vínculos $\mathrm{X}$ percentual da folha com pessoal

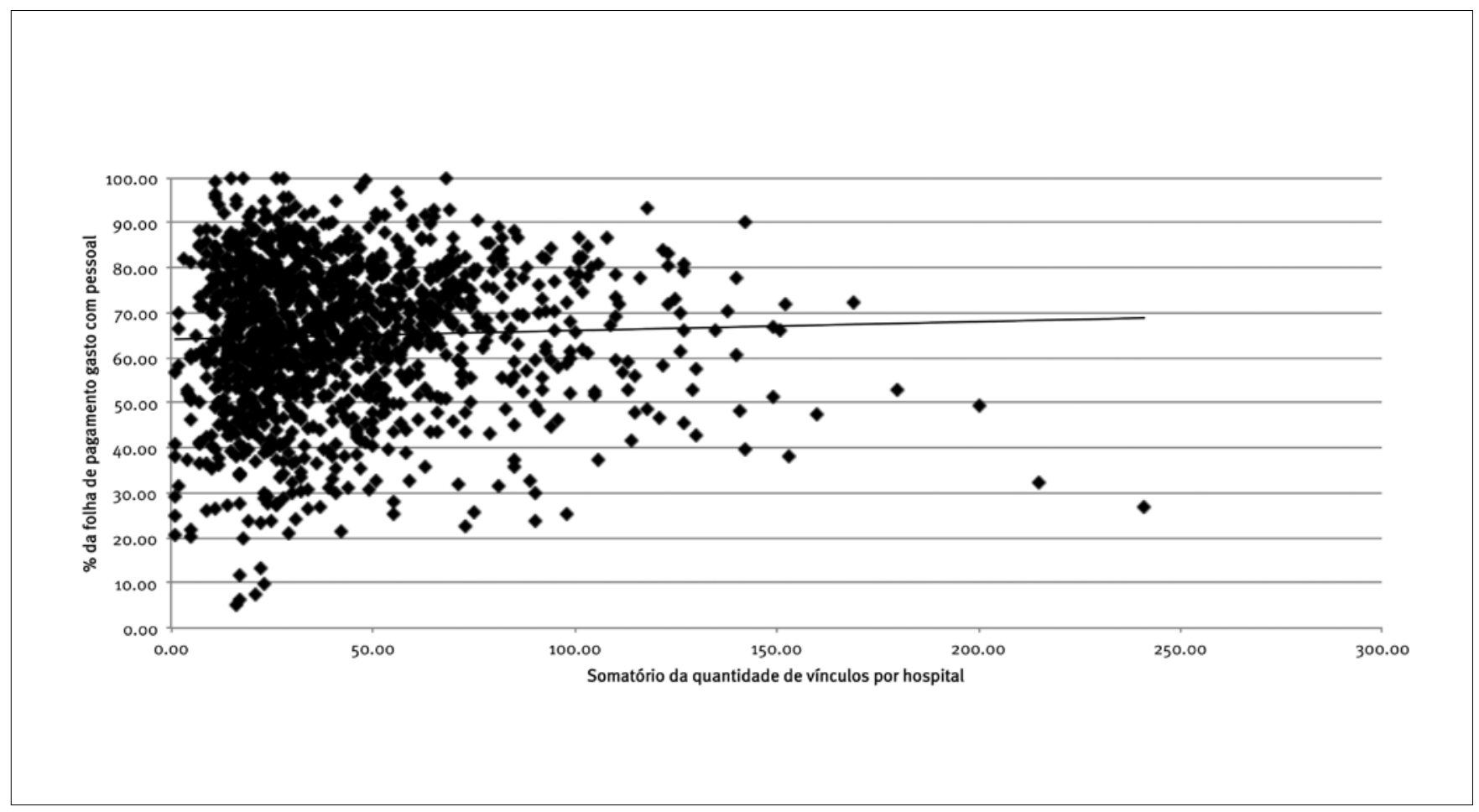


Essa constatação, qual seja de que os HPP apresentam dispêndio elevado com folha de pagamento, ao mesmo tempo em que encontra ressonância nos estudos internacionais, sugere dificuldades para inserção desses hospitais no contexto do SUS.

Com efeito, investigações adicionais podem ser direcionadas visando relacionar, por exemplo, as restrições que os vínculos podem determinar no cuidado à saúde. No campo gerencial, estudar a viabilidade de carreiras de saúde nesses estabelecimentos é uma dimensão que merece maior aprofundamento, considerando as restrições orçamentárias e fiscais existentes no contexto macroeconômico.

Naturalmente, são perspectivas reflexivas e também aplicadas que poderiam apontar alternativas de sustentabilidade tanto no plano assistencial, visando à sua plena inserção às redes de saúde, quanto no organizativo e financeiro, na medida em que são necessários novos arranjos capazes de mitigar as dificuldades e a pulverização existentes.

Os dados sobre vínculos, mesmo relevantes na lógica de pensar a gestão de recursos humanos, não se dissociam dos aspectos gerais dos HPP quanto à sua estrutura e modelo de atenção à saúde, podendo também abrir a possibilidade de um debate sobre qual o formato ou padrão considerado ótimo para garantir o atendimento à saúde.

Considerando o volume de informações que podem ser trabalhadas a partir desta descrição, é possível afirmar que estudos sobre a relação entre vínculo e resultados de saúde, por exemplo, devem ser estimulados e desenvolvidos. Embora não seja possível demarcar com precisão os efeitos diretos dessa situação de vínculo, construir métricas que possam indicar se mais ou menos práticas de recursos humanos, vínculos mais ou menos permanentes, pode proporcionar reflexões sobre uma situação de saúde melhor para os usuários do sistema no Brasil.

De maneira conclusiva, é necessário, em primeiro lugar, estabelecer como ponto de partida para qualquer debate sobre recursos humanos em geral, e em particular na esfera da saúde, a fixação de bases de dados gerais capazes de captar, com algum grau de aproximação, a realidade sempre dinâmica presente nesse fenômeno organizacional. Concomitante a isso, buscar a inter-relação entre campos temáticos do conhecimento torna o debate mais consistente e desvinculado de uma lógica endógena, isto é, que olha somente para o fenômeno, deixando à margem o entorno das relações sociais, econômicas, epidemiológicas, políticas e jurídicas que perpassam a discussão.

Como segunda conclusão, o debate sobre vínculos profissionais sugere que sua influência sobre os resultados da saúde está longe de ser consensual. Com efeito, embora pensar a saúde numa lógica de rede seja primordial, os diferentes níveis de atenção previstos no modelo de saúde brasileiro deixam em aberto qual a forma mais adequada e/ou que melhor responda às necessidades da população. Ou seja, pensar em vínculos exclusivamente estatutários, CLT ou outros formatos não permite conclusões definitivas acerca das formas mais adequadas de gerenciamento e sua relação com as dimensões de atenção à saúde. Da mesma forma, as práticas de gestão de recursos humanos, ao manterem uma dinâmica que reage às formas de contratação, acabam por não estar diretamente vinculadas às demandas da saúde.

\section{REFERÊNCIAS}

Armstrong-Stassen, M., \& Schlosser, F. (2010). When hospitals provide HR practices tailored to older nurses, will older nurses stay? It may depend on their supervisor. Human Resource Management Journal, 20(4), 375-390. doi:10.1111/j.1748-8583.2010.00143.x

Bach, S., \& Givan, R. C. (2010). Regulating employment conditions in a hospital network: The case of the Private Finance Initiative. Human Resource Management Journal, 20(4), 424-439. doi:10.1111/j.17488583.2010.00142.x

Bryman, A., \& Bell, E. (2011). Business research methods (3th ed.). New York, EUA: Oxford University Press.

Chaisiri, K. (1997). Human resource development through continuous improvement: A case study of Yasothon Hospital. Thailand (1994-1997). Recuperado de http://www.who.int/hrh/en/HRDJ_2_2_06.pdf

Conselho Nacional de Secretários Estaduais de Saúde. (2004). Estruturação da área de recursos humanos nas secretarias de saúde dos estados e do Distrito Federal. Brasília, DF.

El-Jardali, F., Tchaghchagian, V., \& Jamal, D. (2009). Assessment of human resources management practices in Lebanese hospitals. Human Resources for Health, 7(84), 1-9. doi:10.1186/1478-4491-7-84

Facchini, L. A., \& Barbosa, A. C. Q. (Coords.). (2014). Estudo de hospitais de pequeno porte brasileiros: Diagnóstico, avaliação $e$ espacialização. Relatório de pesquisa. Belo Horizonte, MG/Pelotas, RS: UFPel/ Observatório de Recursos Humanos em Saúde da FACE/ UFMG.

Fleury, S. (2011, Maio 9). Reforma dos serviços de saúde no Brasil: Movimentos sociais e sociedade civil. The Lancet Saúde no Brasil. doi:10.1016/S0140- 6736(11)60318-8

Grimshaw, D., Rubery, J., \& Marchington, M. (2010). Managing people across hospital networks in the UK: Multiple employers and the shaping of HRM. Human Resource Management Journal, 20(4), 407423. doi:10.1111/j.1748-8583.2010.00144.x

Gupta, N., \& Dal-Poz, M. (2009). Assessment of human resources for health using cross-national comparison of facility surveys in six countries. Human Resources for Health, 7(22), 1-9. doi:10.1186/14784491-7-22 
Instituto Brasileiro de Geografia e Estatística. (2003). Estatísticas da Saúde-Assistência Médico Sanitária 2002. Rio de Janeiro: IBGE.

Khatri, N., Wells, J., McKune, J., \& Brewer, M. (2006, Fall). Strategic human resource management issues in hospitals: A study of a university and a community hospital. Hospital Topics, 84(4), 9-20. doi:10.3200/HTPS.84.4.9-20

LaForgia, G. M., \& Couttolenc, B. (2009). Desempenho hospitalar no Brasil: Em busca da excelência. São Paulo, SP: Singular.

Loan-Clarke, J., Arnold, J., Coombs, C., \& Hartley, R. (2010). Retention, turnover and return: A longitudinal study of allied health professionals in Britain. Human Resource Management Journal, 20(4), 391-406. doi:10.1111/j.1748-8583.2010.00140.x

López, E. M. (2004). Uma revisão do papel dos hospitais de pequeno porte no SUS (Dissertação de mestrado). Rio de Janeiro, RJ: ENSP/ Fiocruz.

Nogueira, R. P. (2002). O trabalho em saúde: Novas formas de organização. In B. Negri, R. Faria, \& A. L. D. Viana (Orgs.), Recursos humanos em saúde: Política, desenvolvimento e mercado de trabalho. Campinas, SP: Unicamp/IE.

Nogueira, R. P., Baraldi, S., \& Rodrigues, V. de A. (2004). Limites críticos das noções de precariedade e desprecarização do trabalho na administração pública. In A. F. R. Barros, J. P. Santana, \& P. M. S. Neto(Orgs.), Observatório de recursos humanos em saúde no Brasil: Estudos e análises. Brasília, DF: Ministério da Saúde.

Organização Pan-Americana de Saúde (2001, Setembro, 24-28). Desenvolvimento e fortalecimento da gestão dos recursos humanos no setor da saúde. 430 Conselho Diretor, 53a Sessão do Comitê Regional. Washington DC, USA.

Paim, J. S. (1994). A reforma sanitária e os modelos assistenciais. In L. M. Vieira-da-Silva (Org.), Saúde coletiva: Textos didáticos (pp. 6182). Salvador, BA: Centro Editorial e Didático, Universidade Federal da Bahia.

Pierantoni, C. R., Varella, T. C., \& França, T. (2004). Recursos humanos e gestão do trabalho em saúde: Da teoria à prática. In A. F. R. Barros, J. P. Santana, \& P. M. S. Neto (Orgs.), Observatório de recursos humanos em saúde no Brasil: Estudos e análises. Brasília, DF: Ministério da Saúde.
Posnett, J. (2002). Are bigger hospitals better? In M. McKee, \& J. Healy (Eds.), Hospitals in a changing Europe. Buckingham: Reino Unido Open University Press.

Rodrigues, R. B. (2008). Atração e retenção e a lógica da gestão de recursos humanos: Um estudo sobre os médicos do programa de saúde da família (PSF) em Belo Horizonte (Dissertação de mestrado). Belo Horizonte, MG: FACE/UFMG.

Rondeau, K., \& Wagar, T. (2002). Reducing the hospital workforce: What is the role of human resource management practices? Hospital Topics, 8o(1), 12-18. doi:10.1080/00185860209597921

Seixas, P. H. (2006). Médicos em saúde da família na cidade de São Paulo. Recuperado de http://www.observarhsp.org.br/projetos/ textos/1rota_cargos_ses.html

Selltiz, C., Jahoda, M., Deutsch, M. , Cook, S.W. (1974). Métodos de pesquisa nas ciências sociais. São Paulo, SP: E.P.U.

Silva, N. C., Rodrigues, R. B., Rocha, T. A. H., \& Rodrigues J. M. (2009). Gestão de recursos humanos em saúde e sua necessária interface ao mundo organizacional: Um olhar ampliado. XXXIII Encontro da ANPAD, São Paulo, SP.

Tabibi, S. J., Vatankhah, S., Nasiripour, A. A., Vahdat, S., \& Hessa, M. S. (2011). Factors affecting planned human resource development in the Iranian social security organization's hospitals. International Journal of Management and Business Research., 1(2), 47-52.

Townsend, K., \& Wilkinson, A. (2010). Managing under pressure: HRM in hospitals. Human Resource Management Journal, 20(4), 332-338. doi:10.1111/j.1748-8583.2010.00145.x

Ugá, M. A. D., \& Lopez, E. M. (2007, August). Os hospitais de pequeno porte e sua inserção no SUS. Ciência \& Saúde Coletiva, 12(4), 915928. doi:10.1590/S1413-81232007000400013

Veillard, J.. Champagne, F., Klazinga, N., Kazandjian, V., Arah, O. A., \& Guisset, A.-L. (2005). A performance assessment framework for hospitals: The WHO regional office for Europe PATH project. International Journal for Quality in Health Care, 17(6), 487-496. doi:10.1093/intqhc/mzio72

Vieira, M. (2005). A gestão do trabalho no Sistema Único de Saúde. Textos de apoio em políticas de saúde. Fundação Oswaldo Cruz. Escola Politécnica de Saúde Joaquim Venâncio. Rio de Janeiro, RJ: Fiocruz. 